\title{
Zn-EDTA DEGRADATION BY CATECHOL-DRIVEN FENTON REACTION
}

\author{
Claudia Oviedo* \\ Departamento de Química, Universidad del Bío-Bío, Avda. Collao 1202, Concepción, Chile \\ Alexander Berrocal y José Navarrete \\ Facultad de Ingeniería, Universidad del Bío-Bío, Avda. Collao 1202, Concepción, Chile \\ Héctor Mansilla y David Contreras \\ Facultad de Ciencias Químicas, Cp 160-C, Universidad de Concepción, Chile
}

Recebido em 1/2/12; aceito em 23/5/12; publicado na web em 24/8/12

\begin{abstract}
Zn-EDTA degradabilty by catechol-driven Fenton reaction was studied. Response surface methodology central composite design was employed to maximize this complex degradation. Theoretical speciation calculations were in good agreement with the experimental results. Fenton and Fenton type treatments are typically thought to be applicable only in the highly acidic range, representing a major operational constraint. Interestingly, at optimized concentrations, this CAT-driven Fenton reaction at pH 5.5 achieved 100\% Zn-EDTA degradation; $60 \%$ COD and $17 \%$ TOC removals, using tiny amounts of CAT $(50 \mu \mathrm{M}), \mathrm{Fe}$ (III) $(445 \mu \mathrm{M})$ and $\mathrm{H}_{2} \mathrm{O}_{2}(20 \mathrm{mM})$ with no evident ferric sludge.
\end{abstract}

Keywords: cathecol-driven Fenton; treatment; Zn-EDTA.

\section{INTRODUCTION}

The chelating agent EDTA (ethylenediaminetetraacetic acid) is a synthetic, highly stable, powerful chelating agent and a widely used compound with industrial and household applications. Indeed, EDTA is of one the most abundant anthropogenic compounds in surface waters being a good marker of anthropogenic pollution in inland waters. ${ }^{1-4}$ Moreover, this complexing agent has been widely used for chemical cleaning of the steam generator internals in nuclear power plants. ${ }^{5}$ Therefore, for decades, leaching of radionuclide and migration to the environment, along with the potential impact of radionuclide-EDTA speciation and degradability, have been of concern. ${ }^{6,7}$

As EDTA is not degraded or removed in conventional waste water treatments, a broad variety of investigations on EDTA degradation and its metal complexes in aqueous solutions, have been performed. Among them, advanced oxidation processes (AOPs), i.e. processes that yield highly oxidant radicals, such as hydroxyl radical $(\mathrm{OH} \bullet)$, have been tried in an effort to degrade EDTA in aqueous solutions. ${ }^{8}$ Therefore, research on technologies to treat common metal-EDTA complexes is of interest. ${ }^{9} \mathrm{Zn}$-EDTA degradability has been poorly assessed and evidence has shown that the complex is not as prone to degradation, by Fenton type treatments, as other metal complexes studied..$^{10}$

Due to its presence in metal plating effluents and automotive wastewaters, ${ }^{11,12}$ and also given its agricultural use and detection in inland waters, ${ }^{13,14}$ the complex can be considered both a point-source and non-point source pollutant. In terms of environmental behavior, Nowack ${ }^{13}$ evaluated the speciation of EDTA in river water, and found that the most prominent species present were Zn-EDTA and $\mathrm{Fe}(\mathrm{III})$-EDTA.

Some Fenton-type reactions include small amounts of both iron (III) and reducing 1,2-dihydroxybenzenes (DHB) such as catechol (CAT). In addition, the Fenton reaction is promoted by reduction of $\mathrm{Fe}$ (III) to $\mathrm{Fe}(\mathrm{II})$ via CAT. Moreover, $\mathrm{OH} \bullet$ radical production is highly enhanced by the Fe(III)-CAT complex effect. ${ }^{15}$ This paper presents the application of a CAT-driven Fenton treatment to assess Zn-EDTA degradability and to determine improved conditions for abatement.

*e-mail: coviedo@ubiobio.cl

\section{EXPERIMENTAL}

All experiments and analyses used nanopure water and all reagents were p.a. grade. Zn-EDTA complex was purchased from Riedel-deHaën. $\mathrm{Fe}_{2}\left(\mathrm{SO}_{4}\right)_{3}$. Catechol and bovine liver catalase were purchased from Sigma. $\mathrm{KH}_{2} \mathrm{PO}_{4}, \mathrm{NaOH}, \mathrm{H}_{2} \mathrm{SO}_{4}$ and $\mathrm{H}_{2} \mathrm{O}_{2}(30 \%)$ aqueous solution were from Merck.

\section{EDTA degradation rate}

Degradation rate was monitored by reverse phase ion paired High Performance Liquid Chromatography (HPLC) analysis. A Merck-Hitachi HPLC system was used having a Lichrocart 125-4/ Lichrosphere $100 \mathrm{RP}-18$ (5 $\mu \mathrm{m}$ particle diameter) column, a constant flow of $1 \mathrm{~mL}^{-1}$ by a HPLC pump (Merck-Hitachi L-6200A), and an autosampler (Merck-Hitachi AS-4000), with a $20 \mu \mathrm{L}$ sample loop. Detection was performed with an UV-Vis detector (Merck-Hitachi L4250-UV-VIS) at $258 \mathrm{~nm}$, equipped with interface and software for the chromatographic data (D-6000 Merck-Hitachi). The detection relies on the spectrophotometric absorption of Fe(III)-EDTA complex. Therefore, all HPLC detection was performed based on protocols previously reported by Nowack et al.. ${ }^{16}$

\section{Organic content determinations}

Chemical Oxygen Demand (COD) was assessed spectrophotometrically via dichromate digestion in a Merck TR-300 thermoreactor. In order to avoid any peroxide interference in COD determinations, a final dose of $0.018 \mathrm{mg} \mathrm{mL}^{-1}$ of catalase (previously dissolved in 0.05 M phosphate buffer) was added to each sample and corrected accordingly. Hydrogen peroxide absence was confirmed by Merckoquant ${ }^{\circledR}$ peroxide test strips in each sample. Total Organic Carbon (TOC) analysis: the complex mineralization rate was determined using a Total Carbon analyzer (TOC-5000; Shimadzu Co.; Ltd. Japan), immediately after each treatment.

All the experiments were carried out following the experimental parameter ranges and modalities previously described by Oviedo $e t$ al..${ }^{17}$ Briefly, treatments consisted of $125 \mathrm{~mL}$ Erlenmeyer flasks with 
a final volume of $25 \mathrm{~mL}$ containing Zn-EDTA complex ( $1 \mathrm{mM})$, the appropriate amounts of $\mathrm{CAT}$ and $\mathrm{Fe}(\mathrm{III})$, and $\mathrm{pH}$ were adjusted (with $\mathrm{NaOH}$ or $\left.\mathrm{H}_{2} \mathrm{SO}_{4}\right)$ to obtain the required initial pH. Finally, $\mathrm{H}_{2} \mathrm{O}_{2}(20$ $\mathrm{mM}$ ) was added, and the reaction took place at $25^{\circ} \mathrm{C}, 121 \mathrm{rpm}$, in the dark for $2 \mathrm{~h}$.

\section{Experimental design}

Response surface methodology central composite design was employed to obtain the set of conditions that would maximize degradability and COD removal in Zn-EDTA $(1 \mathrm{mM})$. The influence of the two following variables was studied: $\mathrm{Fe}(\mathrm{III})(340 \mu \mathrm{M}-550 \mu \mathrm{M})$ and $\mathrm{pH}$ (5-6). All the calculations were carried out by Modde ${ }^{\circledR} 7.0$ software.

\section{Speciation calculus}

Metal speciation at different $\mathrm{pH}$ levels was performed using "CHEAQS pro V.2004.1" written by Wilko Verweij (http://home. tiscali.nl/cheaqs/).

\section{RESULTS AND DISCUSSION}

\section{Experimental design}

In an exploratory study using a factorial experimental design, it was apparent that the highest $\mathrm{pHs}$ assayed consistently yielded the best results. Results also confirmed that different CAT concentrations have no significant effect on complex degradation. However, the presence of a tiny amount of CAT $(50 \mu \mathrm{M})$ was imperative for enhanced degradation (data not shown). This type of dependence on CAT has previously been reported for degrading other pollutants. ${ }^{17,18}$ CATdriven Fenton reaction has been found to be more efficient than Fenton reaction, based on $\mathrm{OH} \bullet$ radical and activated species production. ${ }^{19}$

A two-variable ( $\mathrm{Fe}(\mathrm{III})$ and the required initial $\mathrm{pH}$ ) response surface methodology central composite design was employed. The experimental design is shown in Table 1 . The variable values were coded and normalized into unitary values where: -1 is defined as the lowest value of a variable, and +1 as its highest value. From these extreme variable values, the central point (coded 0 ) was set and assayed in triplicate. The star points were distributed at a distance of $n^{1 / 2}$ from the central point, where $\mathrm{n}$ is the number of variables. The influence

Table 1. Experimental and calculated organic content removals of Zn-EDTA by the CAT-driven Fenton reaction in the central composite design (Coded values are bracketed)

\begin{tabular}{ccccc}
\hline Fe III $(\mu \mathrm{M})$ & $\mathrm{pH}$ & $\begin{array}{c}\text { Experimental } \\
\text { results }{ }^{\mathrm{a}}\end{array}$ & $\begin{array}{c}\text { Calculated } \\
\text { results }^{\mathrm{a}}\end{array}$ & $\begin{array}{c}\text { Remanent } \\
\text { TOC }^{\mathrm{b}}\end{array}$ \\
\hline $340(-1)$ & $5(-1)$ & 0.65 & 0.62 & 0.88 \\
$550(+1)$ & $5(-1)$ & 0.67 & 0.62 & 0.88 \\
$340(-1)$ & $6(+1)$ & 0.62 & 0.64 & 0.85 \\
$550(+1)$ & $6(+1)$ & 0.65 & 0.63 & 0.89 \\
$297(-\sqrt{ } 2)$ & $5.5(0)$ & 0.67 & 0.67 & 0.89 \\
$593(+\sqrt{ } 2)$ & $5.5(0)$ & 0.65 & 0.66 & 0.87 \\
$445(0)$ & $4.8(-\sqrt{ } 2)$ & 0.55 & 0.59 & 0.87 \\
$445(0)$ & $6.2(+\sqrt{ } 2)$ & 0.62 & 0.60 & 0.87 \\
$445(0)$ & $5.5(0)$ & 0.40 & 0.41 & 0.85 \\
$445(0)$ & $5.5(0)$ & 0.40 & 0.41 & 0.87 \\
$445(0)$ & $5.5(0)$ & 0.40 & 0.41 & 0.86 \\
\hline${ }^{\mathrm{a}} \mathrm{COD} / \mathrm{COD}_{0}$ (the remaining COD); ${ }^{\mathrm{b}} \mathrm{TOC}^{2} \mathrm{TOC}_{0}$ (the remaining TOC) \\
\hline
\end{tabular}

of the variables $\mathrm{Fe}(\mathrm{III})$ concentration $\left(X_{1}\right)$ and $\mathrm{pH}\left(X_{2}\right)$ was studied. The response $\left(Y^{I}\right)$ was expressed as $\mathrm{COD} / \mathrm{COD}_{0}$ (the remainder of the initial amount of COD).

\section{Optimization of organic content removal}

A quadratic model consistent with the experimental data in the domain analyzed was developed and subsequently used to plot the response surface curves. Table 1 shows the experimental and calculated results from the central composite design applied as the multivariate optimization strategy for Zn-EDTA abatement. In all cases, 100\% EDTA degradation, monitored by HPLC, was achieved.

Table 1 shows that as $\mathrm{Fe}(\mathrm{III})$ and $\mathrm{pH}$ varied within the designed ranges (Table 1, first and second columns), their corresponding experimental COD removal yields were obtained (Table 1, third column). Hence, a quadratic normalized polynomial response to Zn-EDTA degradation (Equation 1) was obtained from the central composite model experiments. $Y^{-1}=2.420( \pm 0.056)+0.006( \pm 0.034) X_{1}-0.021( \pm 0.034) X_{2}-0.456$
$( \pm 0.041) X_{1}{ }^{2}-0.375( \pm 0.041) X_{2}{ }^{2}$

where $X_{1}$ is Fe(III) concentration, $X_{2} \mathrm{pH}$, and $Y^{2}$ is the COD removal yield $\left(\mathrm{COD} / \mathrm{COD}_{0}\right)$.

The polynomial equation revealed no significant effect of first order terms. As the maximum area is close to the central point, the slope of both variables is neutralized at both sides of the parabola. Thus, it is not possible to get information on the behavior of these two variables in an independent manner. The coefficients were normalized in order to compare the relative importance of the model's variables. The error values correspond to a $95 \%$ confidence level.

Reciprocal values of $Y$ i.e $Y^{-1}$ were modeled, since the minimal values for the response variable are of interest (as $Y^{1}$ decreases, maximal COD removal yields are achieved).

A quadratic model explains the behavior within the domain analyzed for the experimental data. The main value, given the normalized magnitude of the coefficient, is due to $X_{1}^{2}$, the second order term of $\mathrm{Fe}$ (III) concentration. This quadratic term of $\mathrm{Fe}(\mathrm{III})\left(X_{l}\right)$ has a negative coefficient, indicating that a minimal value of $Y^{l}$ is reached by this second order function, associated to this variable (i. e. there is a response of maximal COD removal yield). Likewise, the quadratic term of $\mathrm{pH} X_{2}$ has a negative coefficient, meaning that a minimal value of $Y^{1}$ is reached associated to $\mathrm{pH}$ (i. e. there is a response of maximal COD removal yield).

The polynomial predicted responses were close to the experimental values obtained (Table 1, third and fourth columns) with a correlation coefficient of 0.964 . These values, together with those from the ANOVA test, serve as statistical validation of the model.

The response surface is shown in Figure 1. This plot shows a minimum value at $0.4 \mathrm{COD} / \mathrm{COD}_{0}$. The best values for $\mathrm{pH}$ and $\mathrm{Fe}(\mathrm{III})$ concentration were 5.5 and $455 \mu \mathrm{M}$, respectively. At these improved performance conditions, time course COD removal at 15 min intervals was performed in triplicate, reaching $\mathrm{COD} / \mathrm{COD}_{0}$ values of 0.4 after $120 \mathrm{~min}$ (data not shown). There were no interactions between the two studied variables, unlike in other Fenton systems. ${ }^{20}$

Figure 2 depicts the speciation diagram and $\mathrm{pH}$-dependent behavior of the most prominent metal-catecholate species expected in the initial solution, and of the COD degradation obtained by the system. The importance of the $\mathrm{Fe}$ (III) concentration variable is apparent in the speciation analysis shown in Figure 2, where the main species found in the initial solution were the ferric mono and bis catecholate complexes, respectively (a bis-catecholate zinc complex also exists in the initial solution, at negligible amounts). Moreover, considering 


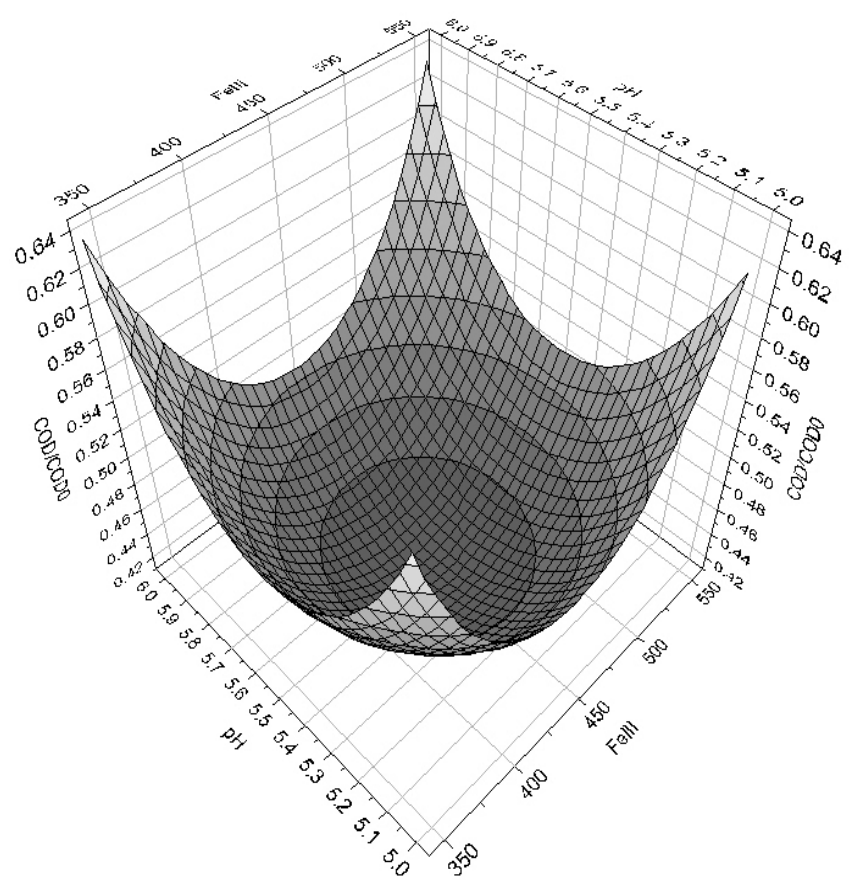

Figure 1. Response surface of COD removal of Zn-EDTA by the CAT-driven Fenton reaction, as a function of $\mathrm{Fe}(\mathrm{III}) \mu \mathrm{M}$ and $\mathrm{pH}$ at $25^{\circ} \mathrm{C}, 2 \mathrm{~h}$ and $\mathrm{CAT}$ $=50 \mu \mathrm{M}$

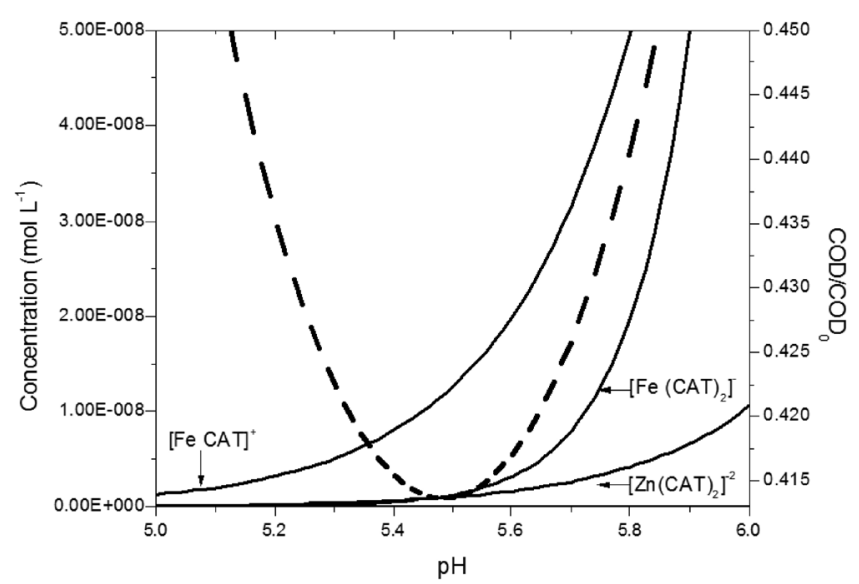

Figure 2. Metal speciation dependence on the initial $p H$ of the reaction and its DOC degradation. (DOC degradation calculated using the polinomial equation)

that the oxidizing ability of the CAT-driven Fenton reaction is based on the reduction of $\mathrm{Fe}(\mathrm{III})$ to $\mathrm{Fe}(\mathrm{II})$ via $\mathrm{CAT}$, and that $\mathrm{OH} \bullet$ radical generation is highly enhanced by the Fe(III)-CAT complex effect, ${ }^{15}$ this $\mathrm{pH}$-dependent behavior of the mono- and the bis- catecholate ferric complexes shown in Figure 2, gains importance.

Previously established observations of the reactivity of the two catecholate ferric complexes described has been reported. ${ }^{15,19}$ Indeed, while the mono-complex $\mathrm{Fe}(\mathrm{CAT})^{+}$is readily reactive and a pro-oxidant, the bi-complex $\mathrm{Fe}(\mathrm{CAT})^{-2}$ is highly stable, acting as an antioxidant, rendering $\mathrm{Fe}$ (III) unavailable for the reaction to proceed.

This phenomenon is in accordance with our findings which show that, as the mono-catecholate ferric complex concentration increases, so does COD removal, whereas as the bis-catecholate complex appears in solution, COD removal begins to decrease (Figure2).

Under the improved treatment conditions, the measured final
$\mathrm{pH}$ was 4.5 , probably due to the formation of organic acids such as oxalic acid identified as degradation products of EDTA by this type of reactions. ${ }^{17}$ Indeed, at this point, the nature of the intermediates could be estimated by the change in the carbon average oxidation state (AOS). The carbon AOS doubled in value to an AOS near (+3); where AOS (+4) corresponds to the most oxidized state of $\mathrm{C}$ $\left(\mathrm{CO}_{2}\right)$, and values of $(+3)$ are due for example, to oxalic acid, among others. ${ }^{21}$ This final reaction environment, rich in organic acids such as oxalic acid, could be amenable to subsequent biological treatment as previously reported..$^{22,23}$

Fenton and Fenton-like treatments normally operate in the highly acidic range. Therefore, $\mathrm{pH}$ adjustment is usually needed before treatment within these processes. Usually, a $\mathrm{pH}$ of around 3 is required, at which Fe(III) is still soluble. These technologies have been applied with varying degrees of effectiveness, also depending on the specific metal coordinated to EDTA. The need for reporting the optimal dose ratio of Fenton's reagents in EDTA degradation has been stated, namely due to adverse effects on the efficiency of the reaction by scavenging effects, among other causes. ${ }^{8} \mathrm{Fu}$ et al., ${ }^{9}$ degraded the Ni-EDTA complex $(8.5 \mathrm{mM})$ by Fenton and ultrasonic treatment, identifying the best parameters as $\mathrm{pH} 3.0 ; \mathrm{Fe}(\mathrm{II})(1 \mathrm{mM})$ and $\mathrm{H}_{2} \mathrm{O}_{2}(141 \mathrm{mM})$ in $1 \mathrm{~h}$. In the present study, multivariate optimization showed the highest $\mathrm{Zn}$-EDTA $(1 \mathrm{mM})$ degradation at $\mathrm{pH}: 5.5$, CAT $(50 \mu \mathrm{M}), \mathrm{Fe}(\mathrm{III})(445 \mu \mathrm{M})$, and $\mathrm{H}_{2} \mathrm{O}_{2}(20 \mathrm{mM})$.

\section{CONCLUSION}

A treatment for Zn-EDTA complex abatement by the CAT-driven Fenton reaction was presented. A quadratic model with good adherence to the experimental data was developed. The RSM composite design identified the improved performance conditions for Zn-EDTA $(1 \mathrm{mM})$ abatement. Interestingly, the best conditions were found at a $\mathrm{pH}$ of 5.5, with tiny amounts of CAT $(50 \mu \mathrm{M})$ and using concentrations of $\mathrm{Fe}(\mathrm{III})$ and $\mathrm{H}_{2} \mathrm{O}_{2}$ of $445 \mu \mathrm{M}$ and $20 \mathrm{mM}$, respectively. The $\mathrm{pH}$ dependence of the most prominent species in solution agrees with the literature, highlighting the importance of the $\mathrm{Fe}(\mathrm{CAT})^{+}$complex in this CAT-assisted Fenton reactions. The CAT-driven Fenton treatment yields $100 \%$ Zn-EDTA degradation, removes 60\% COD and achieves $14 \%$ mineralization, at $\mathrm{pH}$ 5.5. Fenton and Fenton-type treatments are typically thought to be applicable only in the highly acidic range ( $\mathrm{pH} 3$ ), constituting an operational constraint. Therefore, this treatment offers an alternative approach at a more basic $\mathrm{pH}$, with no evident ferric sludge.

\section{ACKNOWLEDGEMENTS}

Financial support from Universidad del Bío-Bío (Grant DIUBB 0837062/R) and FONDECYT (Grant No. 11090312) are gratefully acknowledged.

\section{REFERENCES}

1. Pietsch, J.; Schmidt, W.; Sacher, F.; Fichtner, S.; Brauch, H. J.; Fresenius J. Anal. Chem. 1995, 353, 75.

2. Loyaux-Lawniczak, S.; Douch, J.; Behra, P.; Fresenius J. Anal. Chem. 1999, 364, 727.

3. Oviedo, C.; Rodriguez, J.; Quim. Nova 2003, 26, 901.

4. Bernhard, M.; Muller, J.; Knepper, T. P.; Water Res. 2006, 40, 3419.

5. Park, E. H.; Jung, J. H.; Chung, H. H.; Chemosphere 2006, 64, 432.

6. Means, J. L.; Crerar, D. A.; Duguid, J. O.; Science 1978, 200, 1477.

7. Keith-Roach, M. J.; Sci. Total Environ. 2008, 396, 1.

8. Sillanpää, M.; Kurniawan, T. A.; Lo, W. H.; Chemosphere 2011, 83, 1443. 
9. Fu, F.; Tang, B.; Wang, Q.; Liu J.; Environ. Chem. Lett. 2010, 8, 317.

10. Sillanpää, M.; Pirkanniemi, K.; Sorokin, A.; Environ. Technol. 2009, 30, 1593.

11. Kim, B. R.; Gaines, W. A.; Szafranski, M. J.; Bernath, E. F.; Miles, A. M.; J. Environ. Eng. 2002, 128, 612.

12. Kabdasli, I.; Arslan, T.; Olmez-Hanci, T.; Arslan-Alaton, I.; Tunay, O.; J. Hazard. Mater. 2009, 165, 838.

13. Nowack, B.; Environ. Sci. Technol. 2002, 36, 4009.

14, Gonzalez, D.; Novillo, J.; Rico, M. I.; Alvarez, J. M.; J. Agric. Food Chem. 2008, 56, 3214.

15. Contreras, D.; Rodríguez, J.; Freer, J.; Schwederski, B.; Kaim, W.; J. Biol. Inorg. Chem. 2007, 12, 1055.

16. Nowack, B.; Kari, F. G.; Hilger, S.; Sigg, L.; Anal. Chem. 1996, 68, 561.

17. Oviedo, C.; Contreras, D.; Freer, J.; Rodriguez, J.; Fresenius Environ. Bull. 2003, 12, 1323.
18. Contreras, D.; Oviedo, C.; Valenzuela, R.; Freer, J.; Rojo, K.; Rodriguez, J.; J. Chil. Chem. Soc. 2009, 54, 141.

19. Contreras, D.; Rodriguez, J.; Salgado, P.; Soto-Salazar, C.; Qian, Y.; Goodell, B.; Inorg. Chim. Acta 2011, 374, 643.

20. Rozas, O.; Contreras, D.; Mondaca, M. A.; Perez-Moya, M.; Mansilla, H. D.; J. Hazard. Mater. 2010, 177, 1025.

21. Palominos, R.; Mora, A.; Mondaca, M. A.; Perez-Moya, M., Mansilla, H. D.; J. Hazard. Mater. 2008, 158, 460.

22. Oviedo, C.; Contreras, D.; Freer, J.; Rodríguez J.; Environ. Technol. 2004, 25, 801 .

23. Rodríguez, J.; Contreras, D.; Oviedo, C.; Freer, J.; Baeza, J.; Water Sci. Technol. 2004, 49, 81 . 